\title{
Chitosan from Shellfishes having Promising Biomedical Importance: An Editorial
}

\section{Subha Ganguly*}

AICRP on Post Harvest Technology (ICAR), Department of Fish Processing Technology, Faculty of Fishery Sciences, West Bengal University of Animal and Fishery Sciences, 5, Budherhat Road, P.O. Panchasayar, Kolkata-700 094, WB, India

Chitosan is polysaccharide in nature with linearity in arrangement and composed of $\beta$-(1-4)-linked D-glucosamine (deacetylated unit) and $\mathrm{N}$-acetyl-D-glucosamine (acetylated unit) which remain in a random distribution. Chitin and the derived chitosan, both have potential industrial and biomedical implications for treatment of many ailments in human beings.

Chitosan for use in industrial purpose is extracted from the chitin after deacetylation of chitin which is the major structural element of the exoskeletons of crustaceans and lobsters, prawns and cell wall of fungi [1].

Chitosan finds its application in water treatment plants as a part in the filtration process. It helps in the removal of hardness by the removal of sediments during salt filtration by adsorption of phosphorus, heavy minerals and oils from the water in combination with bentonite, gelatin, silica gel, isinglass or other refining agents. Chitosan also helps in clearing the turbidity in water and also used as a precipitant for casein used for manufacturing cheese from milk [1].

Chotosan in ultrapure form has numerous biomedical implications. Chitosan has mucoadhesive property and so used for intradermal and sustained drug delivery [2], for example, in the administration of insulin in insulin dependent diabetes mellitus. Chitosan is biocompatible and biodegradable which enhances the polar drug transport across epithelial membranes and surfaces [3].

Chitosan coating serve as an antioxidant and micro-diffusion barrier and prevents the loss of water, texture, odor and color thereby improving the overall accessibility of the seafood. The shelf life of Penaeus monodon coated with chitosan dips extend the shelf life of shrimp $[1,4]$.
Chitosan has the property to clot blood and so also used in haemostatic agents for acceleration of wound healing property in humans. Chitosan also possess hypoallergenic and has natural antibacterial properties, which further support its use in field bandages. The flexible nature of chitin is used for making strong and tensile surgical threads having high biodegradability and wound healing property. The antimicrobial property of chitosan is attributed to slightly acidic $\mathrm{pH}[1,4]$.

Chitosan also helps in increased lipid excretion from the body system after interaction and binding with oily components in the digestive tract. Its fat binding property helps in decrease of body mass index especially in obese patients who are advised to be supplemented with the chitosan for nearly 8 weeks continuously for encouraging results $[5,6]$.

\section{References}

1. Bhadra S, Dora KC, Sarkar S, Chowdhury S, Ganguly S (2012) Effect of chitosan coating on shelf life of black tiger shrimp (Penaeus monodon). Explor Anim Med Res 2: 155-165.

2. Agnihotri SA, Mallikarjuna NN, Aminabhavi TM (2004) Recent advances on chitosan-based micro- and nanoparticles in drug delivery. J Control Release 100: 5-28

3. Baldrick P (2009) The safety of chitosan as a pharmaceutical excipient. Regul Toxicol Pharmacol 56: 290-299.

4. Ganguly S (2013) Antimicrobial properties from naturally derived substances useful for food preservation and shelf-life extension- A Review. Int J Bioassays 2: 189-191.

5. Jull AB, Ni Mhurchu C, Bennett DA, Dunshea-Mooij CAE, Rodgers A (2008) Chitosan for overweight or obesity. Cochrane Database Syst Rev (3).

6. Rodríguez MS, Albertengo LE (2005) Interaction between chitosan and oi under stomach and duodenal digestive chemical conditions. Biosci Biotechnol Biochem 69: 2057-2062.
*Corresponding author: Subha Ganguly, AICRP on Post Harvest Technology (ICAR), Department of Fish Processing Technology, Faculty of Fishery Sciences, West Bengal University of Animal and Fishery Sciences, 5, Budherhat Road, P.O. Panchasayar, Kolkata-700 094, WB, India, E-mail: ganguly38@gmail.com

Received July 23, 2013; Accepted July 27, 2013; Published July 29, 2013

Citation: Ganguly S (2013) Chitosan from Shellfishes having Promising Biomedical Importance: An Editorial. Adv Pharmacoepidemiol Drug Saf 2: e122. doi:10.4172/2167-1052.1000e122

Copyright: (c) 2013 Ganguly S. This is an open-access article distributed under the terms of the Creative Commons Attribution License, which permits unrestricted use, distribution, and reproduction in any medium, provided the original author and source are credited. 